\title{
Visualisation of Students' Academic Performance Using Human Learning System
}

\author{
${ }^{1}$ Asabe Sandra Ahmadu PhD, ${ }^{2}$ Etemi Joshua Garba PhD, ${ }^{3}$ Ally Dauda Ahmadu \\ ${ }^{1,2}$ Department of Computer Science, Modibbo Adama University Yola, Nigeria \\ ${ }^{3}$ ICT Centre, Federai University Wukari, Nigeria
}

\begin{abstract}
Data miming (DM) is the technique employed in extracting relevant knowledge from data. While Educational data mining (EDM) is concerns with developing methods that will learn from the extracted knowledge that come from educational environment. The main objective of this paper is to design and develop programs and give recommendations based on the outcomes to help the University management take proactive measures on the causes of students' poor performance based on the discoveries made. We extracted seven hundred and forty-three (743) records collected from four sampled schools: School of Physical Sciences, (SPS), School of Environmental Studies (SES), School of Technology and Science Education (STSE), School of Agriculture and Agricultural Technology (SAAT) all from the Modibbo Adama University of Technology, Yola Nigeria. The Human Learning (HL) system in our model 'Framework for Evaluating Academic Performance (FEAP) to come up in our paper titled' in London Journal of Research in Computer Science and Technology, was made use of in this paper for the DM task which charts: Performance (in percentage) below/above average departmentally, Performance (in percentage) by class of degree departmentally, Performance of students (in percentage) by Mode of Entry departmentally. It made use of SQL server for the extraction of knowledge and Visual studio for charting the extracted knowledge for human visualisation. We were able to improve on how WEKA visualise data; from displaying single query charts to displaying multiple queries charts for a better performance evaluation in an inter phase that enable a user to select either WEKA GUI or HL GUI.
\end{abstract}

Keywords: Visualisation of Students, Academic, Human Learning System, GUI, Data Mining.

\section{INTRODUCTION}

Educational Data Mining is concerned with developing new methods for discovering knowledge from educational database and can be used for decision making in educational system (Pal and Pal 2013). Students are the main assets of universities/Institutions. Students' good performance plays an important role in producing the best quality graduates who will become the manpower force for a country thus responsible for the country's economic development. Production of unbaked graduates from universities who will constitute the most important productive force to the society can have adverse effect on a nation's development and detrimental to lives. These graduates are also capable of replicate their breeds when employed to mentor or train the younger generations coming up.

The yardstick for majoring performance of students in higher institutions is CGPA; this index gives the overall average performance of students' examinations' grade within the time frame in the university (Clare, B et al, 2021). The main functions of data mining are applying various methods and algorithms in order to discover and extract patterns of stored data (Fayadd et al. 1996) Many factors could act as barrier or catalyst to students achieving a high CGPA that reflects their overall academic performance (Yadav et al. 2012). We have combined some of these factors with performance in our query statements, filtered and chart the outcomes so as to visualise the patterns each combination gave from the data sets mined.

The discovered knowledge can be used to offer helpful and constructive recommendations to the academic planners in higher education institutes to enhance their decision-making process, to improve students' academic performance and trim down failure rate, to better understand students' behaviour, to assist instructors, to improve teaching and many other benefits (Kumar and Chadha 2011).

\section{LITERATURE}

\subsection{SQL}

SQL stands for Structured Query Language. SQL is used to communicate with a database; it is the standard language for relational database management systems. Some common relational database management systems that use SQL are: Oracle, Sybase, Microsoft SQL Server, Access, Ingres, etc. There are no variables in SQL, everything about an SQL query must be specific - the literal values, the column names, and the table names (AbbasI, 2005). 
ISSN (online): 2581-3048

Volume 5, Issue 7, pp 66-72, July-2021

https://doi.org/10.47001/IRJIET/2021.507012

\subsection{Distillation of Data for Human Judgment}

Another area of interest within educational data mining is the distillation of data for human judgment. In some cases, human beings can make inferences about data, when it is presented appropriately, that are beyond the immediate scope of fully automated data mining methods. The methods in this area of educational data mining are information visualization methods however, the visualizations most commonly used within EDM are often different than those most often used for other information visualization problems (Hershkovitz \& Nachmias, 2008), owing to the specific structure, and the meaning embedded within that structure, often present in educational data (Christopher, C. Y, et al, 2021).

\subsection{User interface issues}

Data mining tool become attractive when it is aesthetic, easily interpreted, and user friendly. Many data exploratory analysis tasks are significantly facilitated by the ability to see data in an appropriate visual presentation. The major issues related to user interfaces and visualization are "screen realestate", information rendering and interaction. (Osmar and Zaïane 1999). Interaction of data and data mining tools provides hidden knowledge that can only be accessed and understood by professionals. Data entry or transformation platforms are accessed through this medium, solutions are also proffered through same.

\subsection{Visualisation}

Visualisation is a tool used to make results obtained represented in a graphical view for easier understanding and comprehension. It enables a user picture the Discovered knowledge from different perspectives and conceptual levels. Visualization also helps determine difficulty of the learning problem. WEKA can visualize single attributes (1-d) and pairs of attributes (2-d), rotate 3-d visualizations (Xgobi-style). WEKA has "Jitter" option to deal with nominal attributes and to detect "hidden" data points (Aksenova, 2004). WEKA also lets you to visualize classification errors.

\section{METHODOLOGY}

\subsection{Techniques and Methods}

In this work, we used the following methods and tools to help solve the problems indentified in the study;

i) Data Extraction

ii) Applying SQL Queries in order to filter hidden knowledge

iii) Using Visual Studio to plot charts on the extracted knowledge

iv) Human Learning Model

\subsection{Sample of SQL Statements}

The following SQL statement counts Performance Below and Above Average departmentally

SELECT dbo.AB_Ave.DEPARTMENT,

ISNULL(dbo.AB_Ave.ABOVE_AVERAGE, 0) AS ABOVE_AVERAGE,

ISNULL(dbo.BL_AV.BELOW_AVERAGE, 0) AS

BELOW_AVERAGE

FROM dbo.AB_Ave LEFT OUTER JOIN

dbo.BL_AV ON dbo.AB_Ave.DEPARTMENT = dbo.BL_AV.DEPARTMENT

Count of Performance by Class of Degree departmentally

SELECT dbo.SECOND_CLASS.DEPARMENT, dbo.SECOND_CLASS.FIRST_CLASS, dbo.SECOND_CLASS.SECOND_CLASS_UPPER, dbo.SECOND_CLASS.SECOND_CLASS_LOWER,

ISNULL(dbo.THIRD_CLASS.THIRD_CLASS, 0)

AS THIRD_CLASS,

ISNULL(dbo.PASS_DEGREE.PASS_DEGREE, 0) AS PASS

FROM dbo.PASS_DEGREE INNER JOIN

dbo.THIRD_CLASS ON

dbo.PASS_DEGREE.DEPARTMENT = dbo.THIRD_CLASS.DEPARTMENT RIGHT OUTER JOIN

dbo.SECOND_CLASS ON dbo.THIRD_CLASS.DEPARTMENT $=$ dbo.SECOND CLASS.DEPARMENT

Count of Performance by Mode of Entry departmentally

SELECT dbo.AboveAverage_EntryMode.DEPARTMENT, ISNULL(dbo.AboveAverage_EntryMode.ABOVE_A VERAGE_DE, 0) AS ABOVE_AVERAGE_DE, ISNULL(dbo.AboveAverage_EntryMode.ABOVE_A VERAGE_UTME, 0)

AS ABOVE_AVERAGE_UTME, ISNULL(dbo.AboveAverage_EntryMode.AboveAver age_PreDegree, 0) AS ABOVE_AVERAGE_PRE_DEGREE, ISNULL(dbo.Below_Average_EntryMode.BELOW_ AVERAGE_DE, 0)

AS BELOW_AVERAGE_DE, ISNULL(dbo.Below_Average_EntryMode.BELOW_ AVERAGE_UTME, 0) AS BELOW_AVERAGE_UTME, 
ISSN (online): 2581-3048

ISNULL(dbo.Below_Average_EntryMode.BELOW_ AVERAGE_PRE_DEGREE, 0)

\section{AS}

BELOW_AVEARAGE_PREE_DEGREE

FROM dbo.AboveAverage_EntryMode LEFT OUTER JOIN

dbo.Below_Average_EntryMode ON dbo.AboveAverage_EntryMode.DEPARTMENT = dbo.Below_Average_EntryMode.DEPARTMENT

Count of Performance by Gender departmentally

SELECT dbo.FEMALE_VIEW.DEPARTMENT, dbo.FEMALE_VIEW.ABOVE_AVERAGE_FEMA LE,

dbo.FEMALE_VIEW.BELOW_AVERAGE_FEMA LE, dbo.MALE_VIEW.MALE_ABOVE_AV, dbo.MALE_VIEW.MALE_BELOW_AV

FROM dbo.FEMALE_VIEW LEFT OUTER JOIN

dbo.MALE_VIEW ON dbo.FEMALE_VIEW.DEPARTMENT $=$ dbo.MALE_VIEW.DEPARTMENT

Count of Performance by Marital Status

departmentally

SELECT dbo.MARRIED_VIEW.DEPARTMENT, dbo.MARRIED_VIEW.ABOVE_AVERAGE_MAR RIED,

dbo.MARRIED_VIEW.MARRIED_BELOW_AVER AGE,

dbo.SINGLE_BELOW_VIEW.SINGLE_ABOVE_A VEARAGE,

dbo.SINGLE_BELOW_VIEW.SINGLE_BELOW_A VERAGE

FROM dbo.MARRIED_VIEW LEFT OUTER JOIN

dbo.SINGLE_BELOW_VIEW ON dbo.MARRIED_VIEW.DEPARTMENT $=$ dbo.SINGLE_BELOW_VIEW.DEPARTMENT

shows the Count of Performance by Age Group departmentally

SELECT dbo.AGERANGE_1.DEPARTMENT,

ISNULL(dbo.AGERANGE_1.ABOVE_AVERAGE_ BELOW 20, 0) AS

ABOVE_AVERAGE_AGE_BELOW_20, ISNULL(dbo.AGERANGE_1.BELOW_AVERAGE _AGE_20,0)
Volume 5, Issue 7, pp 66-72, July-2021

https://doi.org/10.47001/IRJIET/2021.507012

AS

BELOW_AVERAGE_AGE_BELOW_20, ISNULL(dbo.AGERANGE_1.ABOVE_AVERAGE_ ABOVE_20_TO_30,0) AS

ABOVE_AVERAGE_AGE_20_TO_30, ISNULL(dbo.AGERANGE_1.BELOW_AVERAGE _AGE_20_TO_30,

\section{0) AS}

BELOW_AVERAGE_AGE_20_TO_30, ISNULL(dbo.AGERANGE_2.ABOVE_AVERAGE_ 31_TO_40,0) AS ABOVE_AVERAGE_AGE_31_TO_40, ISNULL(dbo.AGERANGE_2.BELOW_AVERAGE _31_TO_40,0)

\section{AS}

BELOW_AVERAGE_AGE_31_TO_40, ISNULL(dbo.AGERANGE_2.ABOVE_AVERAGE_ AGE_41_TO_55,0) AS

ABOVE_AVERAGE_AGE_41_TO_55,

ISNULL(dbo.AGERANGE_2.BELOW_AVERAGE _AGE_41_TO_55,0)

AS

BELOW_AVERAGE_AGE_41_TO_55

FROM dbo.AGERANGE_1 LEFT OUTER

JOIN

dbo.AGERANGE_2 ON

dbo.AGERANGE_1.DEPARTMENT = dbo.AGERANGE 2.DEPARTMENT

FIRST CLASS

SELECT DEPARTMENT, IS NULL(COUNT(CGPA), 0) AS FIRST_CLASS

FROM dbo.Student_Infor_Tbl

WHERE $\quad($ CGPA $=$ 'GREATER THAN 4.49')

GROUP BY DEPARTMENT

\subsection{Human Learning (HL) Model}

HL is the aspect that is concern with dissemination of informed practice trough various thresholds in SQL. This information can be useful to an individual, committee or management through algorithms that will output results in a visual form.

Parameter queries are written for end users to run. At runtime, the end user is asked to provide specific values for all the variables, like the Faculty, Department and programme. These values are placed in the GUI layer, before the SQL query is sent to the DBMS engine for processing. SQL Parameter query was used in order to make the software 
ISSN (online): 2581-3048

Volume 5, Issue 7, pp 66-72, July-2021 https://doi.org/10.47001/IRJIET/2021.507012

interactive and user friendly, meeting the users' needs instead of rigid query statements that might not meet a particular demand of a user. What has been extracted has been further charted using Visual studio.

\subsection{Performance}

The word performance was used in naming one of the attributes used in the data set as detailed in table 1 below.

\section{DISCUSSION OF RESULTS}

The HL model results have developed using the extracted data that meet specified criteria. The results in the table were the computed percentage of each data item.

Table 2: Performance of Students (in percentage) below and above average, departmentally

\begin{tabular}{|l|c|c|}
\hline DEPARTMENT & PERFORMANCE NO & PERFORMANCE YES \\
\hline Food science and technology & 24 & 76 \\
\hline Architecture & 17 & 83 \\
\hline Geography & 42 & 58 \\
\hline Industrial Design & 36 & 64 \\
\hline Survey and geo-informatics & 33 & 67 \\
\hline Urban Regional Planning & 23 & 77 \\
\hline Computer Science & 14 & 86 \\
\hline Mathematics & 19 & 81 \\
\hline Physics & 0 & 100 \\
\hline STAT/OR & 28 & 72 \\
\hline Science Education & 11 & 89 \\
\hline Technology Education & 21 & 79 \\
\hline Vocational Education & 23 & 77 \\
\hline
\end{tabular}

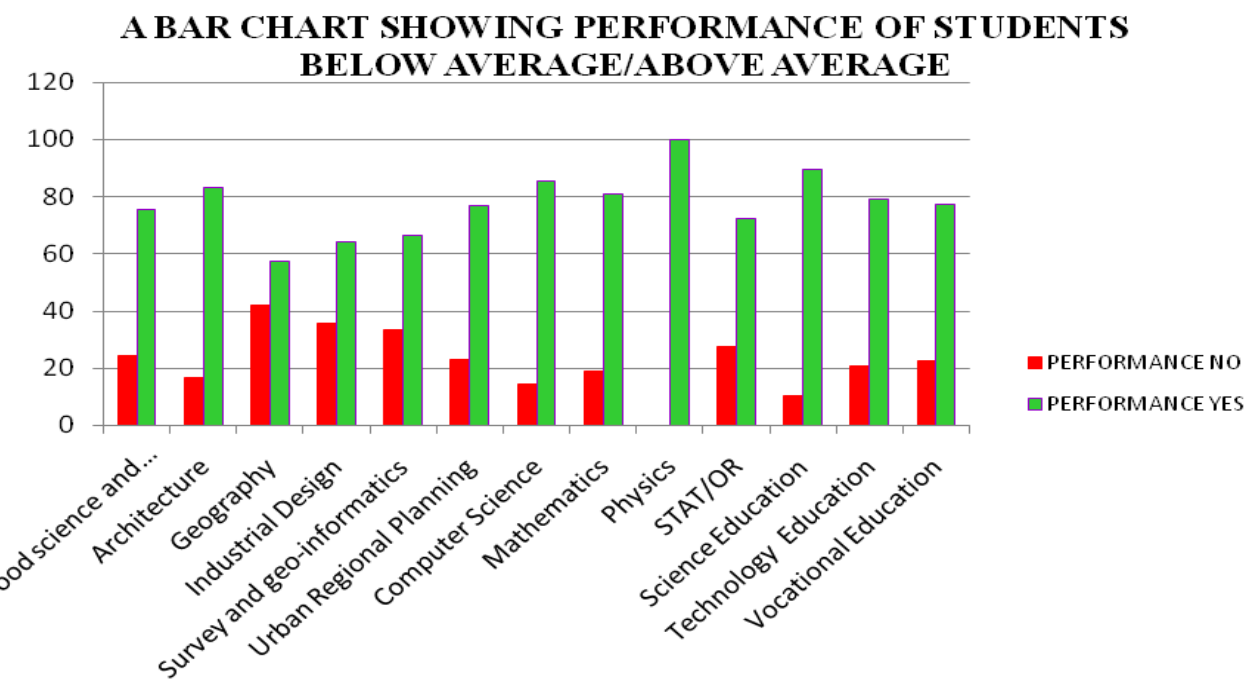

Figure 1: Performance (in percentage) below/above average departmentally 


\subsection{Results Discussion of Figure 1}

The chart in figure 1 above shows that student's performance is commendable except for departments like Geography, Industrial Design, Survey and STAT/OR which need further investigations as to why a large number of students performed below average.

Table 3: Count of Performance by Class of Degree departmentally

\begin{tabular}{|l|c|c|c|c|c|}
\hline DEPARTMENT & $\begin{array}{c}\text { 1st } \\
\text { Class }\end{array}$ & $\begin{array}{c}\text { 2nd Class } \\
\text { Upper }\end{array}$ & $\begin{array}{c}\text { 2nd Class } \\
\text { Lower }\end{array}$ & $\begin{array}{c}\text { Third } \\
\text { Class }\end{array}$ & $\begin{array}{c}\text { Pass } \\
\text { Degree }\end{array}$ \\
\hline Food science and technology & - & 21 & 58 & 18 & 3 \\
\hline Architecture & 4 & 19 & 61 & 11 & 4 \\
\hline Geography & - & 15 & 44 & 25 & 15 \\
\hline Industrial Design & - & 13 & 51 & 29 & 7 \\
\hline Survey and geo-informatics & 4 & 18 & 44 & 31 & 3 \\
\hline Urban Regional Planning & 4 & 27 & 46 & 21 & 2 \\
\hline Computer Science & 3 & 32 & 53 & 11 & 1 \\
\hline Mathematics & 4 & 43 & 34 & 15 & 4 \\
\hline Physics & - & 20 & 30 & 50 & - \\
\hline STAT/OR & 3 & 23 & 42 & 23 & 10 \\
\hline Science Education & 4 & 37 & 49 & 9 & 1 \\
\hline Technology Education & - & 17 & 59 & 21 & 3 \\
\hline Vocational Education & - & 27 & 50 & 23 & - \\
\hline
\end{tabular}

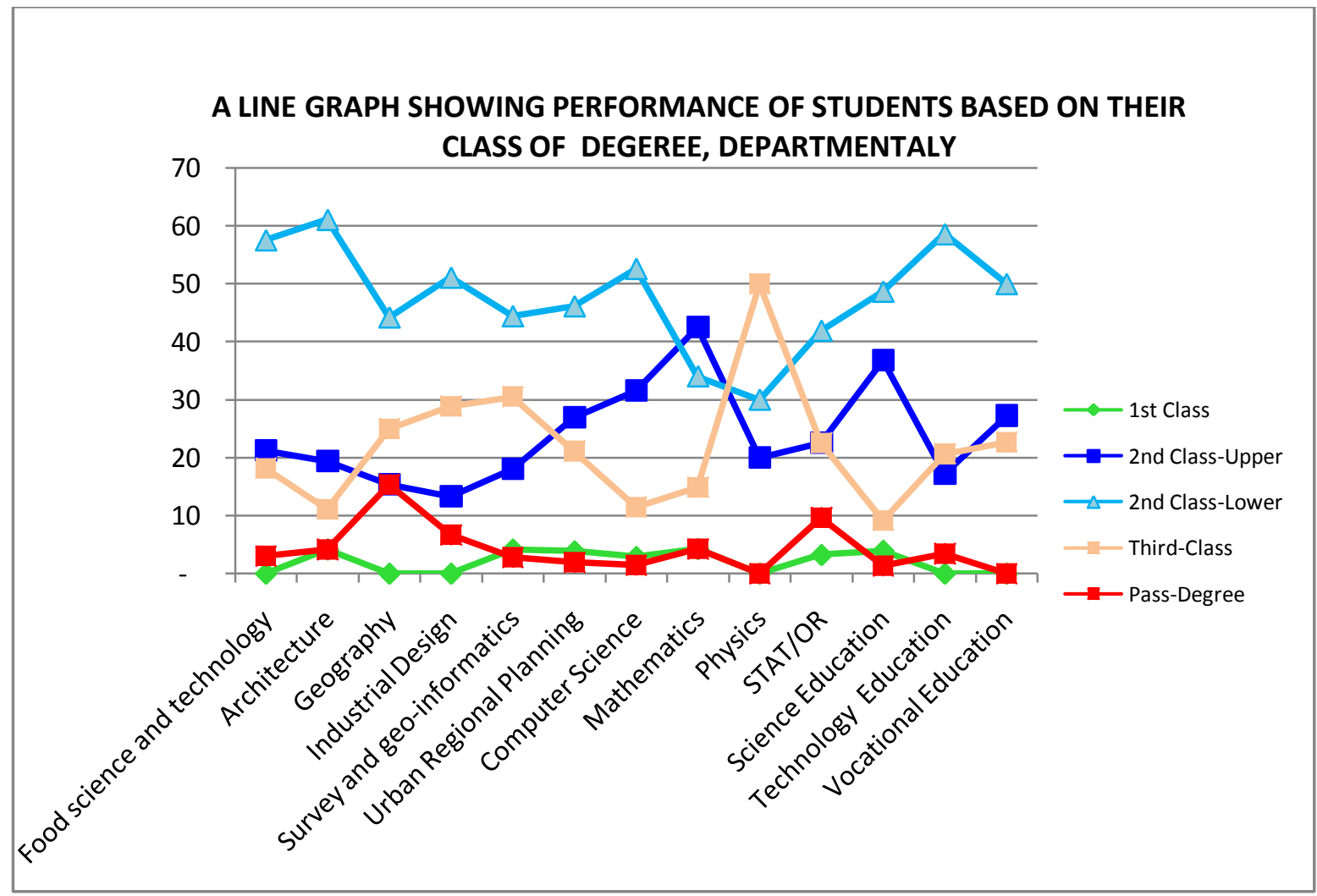

Figure 2: Performance (in percentage) by class of degree departmentally 


\subsection{Results Discussion of Figure 2}

The chart on figure 2 Shows that first class and Pass degree are on the lowest side in all departments; though pass degree seem to be a bit higher in Geography and STAT/OR departments. There are more students that are in the second class lower than any other class except for departments like Mathematics and Physics that their highest population in the Second Class Upper and Third Class respective. There is low occurrence of third class in Architecture, Computer science, Mathematics, Physics and Science education. Survey, Urban and regional planning, Computer science, Physics, and Science education have more number of students with pass degree.

Table 4: Count of Performance by Mode of Entry departmentally

\begin{tabular}{|c|c|c|c|c|c|c|}
\hline Department & $\begin{array}{c}\text { DE } \\
\text { Performance }= \\
\text { No }\end{array}$ & $\begin{array}{c}\text { pre-degree } \\
\text { Performance }= \\
\text { No }\end{array}$ & $\begin{array}{c}\text { UTME } \\
\text { Performance }= \\
\text { No }\end{array}$ & $\begin{array}{c}\text { DE } \\
\text { Performance }= \\
\text { Yes }\end{array}$ & $\begin{array}{c}\text { Pre-Degree } \\
\text { Performance }= \\
\text { Yes }\end{array}$ & $\begin{array}{c}\text { UTME } \\
\text { Performance }= \\
\text { Yes }\end{array}$ \\
\hline $\begin{array}{l}\text { Food science and } \\
\text { technology }\end{array}$ & 6 & 0 & 18 & 30 & 0 & 45 \\
\hline Architecture & 1 & 1 & 14 & 19 & 3 & 61 \\
\hline Geography & 6 & 0 & 37 & 12 & 2 & 44 \\
\hline Industrial Design & 4 & 0 & 31 & 9 & 4 & 51 \\
\hline $\begin{array}{l}\text { Survey and geo- } \\
\text { informatics }\end{array}$ & 6 & 3 & 25 & 8 & 0 & 58 \\
\hline $\begin{array}{l}\text { Urban Regional } \\
\text { Planning }\end{array}$ & 0 & 2 & 21 & 13 & 2 & 62 \\
\hline $\begin{array}{l}\text { Computer } \\
\text { Science }\end{array}$ & 4 & 0 & 10 & 29 & 2 & 55 \\
\hline Mathematics & 4 & 0 & 15 & 26 & 2 & 53 \\
\hline Physics & 0 & 0 & 0 & 60 & 0 & 40 \\
\hline STAT/OR & 17 & 0 & 10 & 34 & 0 & 38 \\
\hline $\begin{array}{l}\text { Science } \\
\text { Education }\end{array}$ & 4 & 0 & 7 & 57 & 0 & 33 \\
\hline $\begin{array}{l}\text { Technology } \\
\text { Education }\end{array}$ & 7 & 0 & 14 & 66 & 0 & 14 \\
\hline $\begin{array}{l}\text { Vocational } \\
\text { Education }\end{array}$ & 14 & 0 & 9 & 55 & 0 & 23 \\
\hline
\end{tabular}

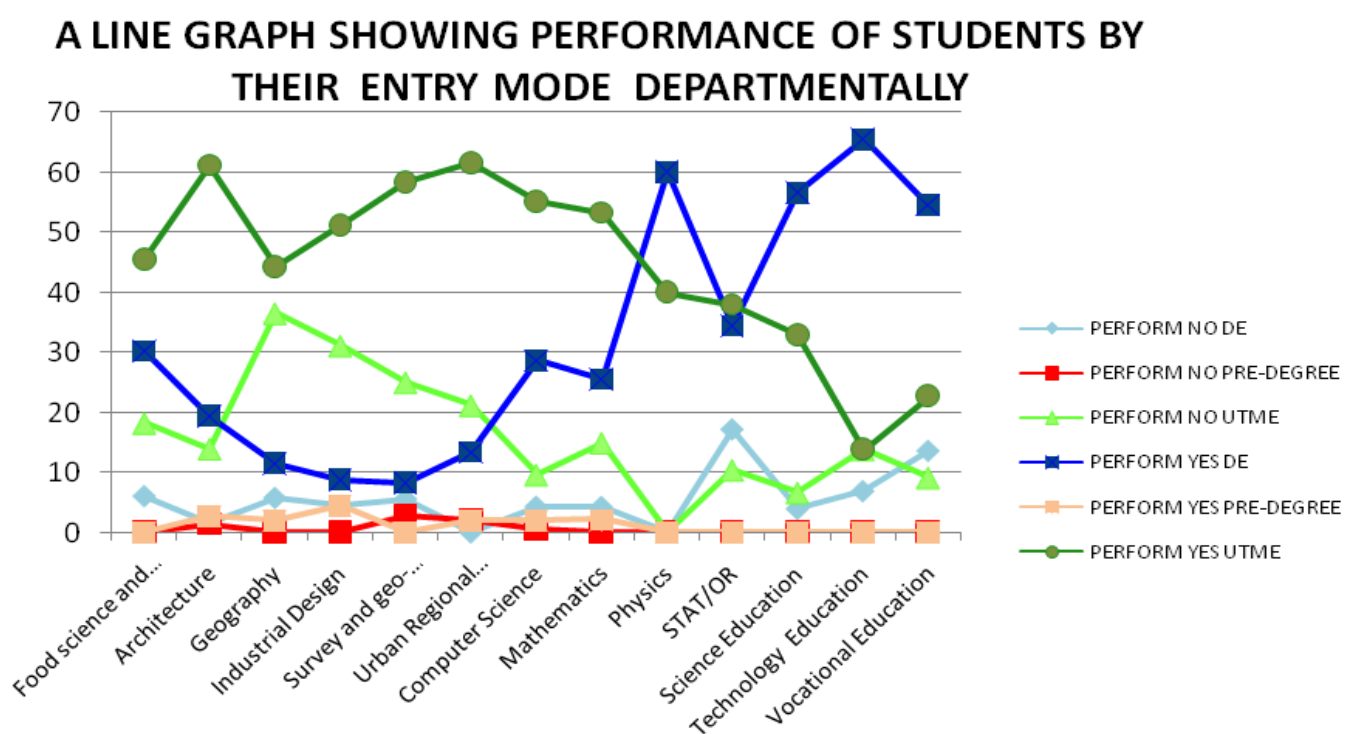

Figure 3: Performance of students (in percentage) by Mode of Entry departmentally 
ISSN (online): 2581-3048

\subsection{Results Discussion of Figure 3}

The figure 4 above shows that students who came through UTME entry have the overall best performance except for Physics and the three educational courses: Science Education, Technology Education and Vocational Education where students who came in through DE outperformed those that came in through other entries. Predegree entry performance is very low; the only two departments that show little evidence of performance are Architecture and Industrial Design.

\section{CONCLUSION}

We were able to show that an efficient Human Learning data mining models is achievable using complex queries that combines performance and other factors that might be of interest to a researcher in order to uncover hidden knowledge that was in a database. The model FEAP demonstrates some of the outcomes of the human learning systems using charts. One of our discoveries in figure 3 is that students that gain entry into the University through UTME i.e. straight from secondary school, perform better than those that took diploma programmes or pre-degree before proceeding to the University. We also discover that National Colleges of Education (NCE) prepare students better for University take off than diploma programmes; though the set back of this could be attributed to the fact that Universities offer diploma programmes that are not well articulated and coordinated. In our future work we shall compare performance of students who gained admissions through University diplomas with those through Polytechnics.

\section{REFERENCES}

[1] Aksenova, S. S. (2004); Machine Learning with WEKA, WEKA Explorer Tutorial Version 3.4.3, School of Engineering and Computer Science Department of Computer Science California State University, Sacramento California, 95819, aksenovs@ecs.csus.edu Retrieved on 15/03/2016.

[2] AbbasI, A. (2005); MS Access 2007 Step by Step,Takveen, Inc. South River, NJ 08882.
[3] Fayyad, U., Piatetsky-Shapiro, G., and Smyth, P. (1996). "From data mining to knowledge discovery in databases", AAAI Press / the MIT Press, Massachusetts Institute of Technology. ISBN 0-262 56097-6.

[4] Hershkovitz, A., Nachmias, R. (2008) Developing a Log-Based Motivation Measuring Tool. Proceedings of the First International Conference on Educational Data Mining, 226-233.

[5] Kumar, V. And Chadha, A. (2011). An Empirical Study of the Applications of Data Mining Techniques in Higher Education (IJACSA) International Journal of Advanced Computer Science and Applications, http://ijacsa.thesai.org Retrieved: 10/06/2014.

[6] Pal, A. K and Pal, S. (2013) Classification Model of Prediction for Placement of Students I. J. Modern Education and Computer Science, pp 49-56 Published Online November 2013 in MECS, http://www.mecspress.org Retrieved on 22/09/2017.

[7] Yadav, S. K., Bharadwaj, B, and Pal, S. (2012) Data Mining Applications: A comparative Study for Predicting Student's performance International Journal Of Innovative Technology \& Creative Engineering (ISSN:2045-711) VOL.1(12) pp 13-19.

[8] Clare, B and Tenzin D. (2021), Educational Data Mining Versus Data Analytics, A Review of Publications From 2015 to 2019, Interactive Learning Environments, DOI, 10.1080/10494820.2021.1943689

[9] Christopher, C. Y, Irene, Y. L and Hiroali O (2021), Educational Technology \& Society Vol 24 No 1, pp $152-183$.

\section{Citation of this Article:}

Asabe Sandra Ahmadu PhD, Etemi Joshua Garba PhD, Ally Dauda Ahmadu, "Visualisation of Students' Academic Performance Using Human Learning System" Published in International Research Journal of Innovations in Engineering and Technology - IRJIET, Volume 5, Issue 7, pp 66-72, July 2021. Article DOI https://doi.org/10.47001/IRJIET/2021.507012 